\title{
Combustion- and Friction-Derived Magnetic Air Pollution Nanoparticles in Human Hearts
}

Lilian Calderón-Garcidueñas MD ${ }^{1,2}$, Angélica González-Maciel MS ${ }^{3}$, Partha S. Mukherjee PhD Rafael Reynoso-Robles BS ${ }^{3}$, Beatriz Pérez-Guillé DMV ${ }^{3}$, Carlos Gayosso-Chávez MD ${ }^{5}$, Ricardo Torres-Jardón $\mathrm{PhD}^{6}$, Janet V. Cross $\mathrm{PhD}^{7}$, Imad A.M. Ahmed $\mathrm{PhD}^{8}$, Vassil V. Karloukovski ${ }^{9}$, Barbara A. Maher $\mathrm{PhD}^{9}$

${ }^{1}$ The University of Montana, Missoula, MT 59812, USA

${ }^{2}$ Universidad del Valle de México, 14370, México

${ }^{3}$ Instituto Nacional de Pediatría, 04530, México

${ }^{4}$ Mathematics Department, Boise State University, Boise, Idaho, 83725, USA

${ }^{5}$ Cardiology Department, Hospital HMG, 04380, Mexico

${ }^{6}$ Universidad Nacional Autónoma de México, 04310, México

${ }^{7}$ Biomedical Sciences Graduate Program, School of Medicine, University of Virginia, Charlottesville, VA, USA

${ }^{8}$ Department of Earth Sciences, University of Oxford, OX1 3AN Oxford, United Kingdom

${ }^{9}$ Centre for Environmental Magnetism and Palaeomagnetism, Lancaster Environment Centre, University of Lancaster, Lancaster LA1 4YQ, United Kingdom.

Funding: In part by SEP-CONACYT 255956. Funding source had no involvement in study design; collection, analysis and interpretation of data; in the writing of the report; and in the decision to submit the article for publication. 
Declarations of interest: none

Correspondence to: Professor Lilian Calderón-Garcidueñas, MA, MD, PhD, University of Montana, 32 Campus Drive, 287 Skaggs Building, Missoula, MT 59812, USA. Tel.: 406-2434785; lilian.calderon-garciduenas@umontana.edu

\begin{abstract}
Air pollution is a risk factor for cardiovascular and Alzheimer's disease (AD). Iron-rich, strongly magnetic, combustion- and friction-derived nanoparticles (CFDNPs) are abundant in particulate air pollution. Metropolitan Mexico City (MMC) young residents have abundant brain CFDNPs associated with $\mathrm{AD}$ pathology. We aimed to identify if magnetic CFDNPs are present in urbanites' hearts and associated with cell damage. We used magnetic analysis and transmission electron microscopy (TEM) to identify heart CFDNPs and measured oxidative stress (cellular prion protein, $\mathrm{PrP}^{\mathrm{C}}$ ), and endoplasmic reticulum (ER) stress (glucose regulated protein, GRP78) in 72 subjects age 23.8 $9.4 \mathrm{y}: 63 \mathrm{MMC}$ residents, with Alzheimer Continuum vs 9 controls. Magnetite/maghemite nanoparticles displaying the typical rounded crystal morphologies and fused surface textures of CFDNPs were more abundant in MMC residents' hearts. NPs, $\sim 2-10$ $\mathrm{x}$ more abundant in exposed vs controls, were present inside mitochondria in ventricular cardiomyocytes, in ER, at mitochondria-ER contact sites (MERCs), intercalated disks, endothelial and mast cells. Erythrocytes were identified transferring 'hitchhiking' NPs to activated endothelium. Magnetic CFDNP concentrations and particle numbers ranged from 0.2 to $1.7 \mu \mathrm{g} / \mathrm{g}$ and $\sim 2$ to $22 \times 10^{9} / \mathrm{g}$, respectively. Co-occurring with cardiomyocyte NPs were abnormal mitochondria and MERCs, dilated ER, and lipofuscin. MMC residents had strong left ventricular $\operatorname{PrP}^{\mathrm{C}}$ and bi-ventricular GRP78 up-regulation.
\end{abstract}


The health impact of up to $\sim 22$ billion magnetic NPs/g of ventricular tissue are likely reflecting the combination of surface charge, ferrimagnetism, and redox activity, and includes their potential for disruption of the heart's electrical impulse pathways, hyperthermia and alignment and/or rotation in response to magnetic fields. Exposure to solid NPs appears to be directly associated with early and significant cardiac damage. Identification of strongly magnetic CFDNPs in the hearts of children and young adults provides an important novel layer of information for understanding CVD pathogenesis emphasizing the urgent need for prioritization of particulate air pollution control.

Key words: air pollution, Alzheimer's Continuum, particulate matter (PM), cardiovascular disease, combustion/friction-derived nanoparticles (CFDNPs), cardiomyocytes, children, Glucose-Regulated Protein 78 (GRP78), heart, oxidative stress, endoplasmic reticulum stress, mitochondrial myocardial damage, cellular prion protein $\operatorname{PrP}^{\mathrm{c}}$, ultrafine $\mathrm{PM}$

\section{Introduction}

Air pollution is a serious public health problem around the world. A critical component of the air pollution mix is particulate matter (PM). Epidemiological studies show that acute and chronic exposures to PM increase the risk for cardiovascular (CV) morbidity and mortality (Dockery et al., 1993; Lucking et al., 2008; Brook et al., 2010; Mills et al., 2011; Rajagopalan et al, 2018; Tibuakuu et al., 2018; Malik et al., 2019). However, the causal links between specific PM components and health impact are not clear; pathways suggested as playing a role in the development, morbidity and mortality of PM-related CV diseases include pulmonary and 
systemic oxidative stress and inflammation, endothelial dysfunction, imbalance of the autonomic nervous system and arrhythmogenesis (Brook et al., 2010; Rajagopalan et al, 2018).

The nanoparticles $(<100 \mathrm{~nm})$ present in airborne pollution may represent a key component with regard to human health impacts. It should be noted that in combustion emission research and atmospheric research sub $100 \mathrm{~nm}$ particles are frequently called ultrafine particles. Their combination of nanoscale dimensions, high surface area and variable chemical and physical properties renders them not only potentially biochemically reactive but also readily able to access human organs, cells and sub-cellular structures. Critically, although nanoparticles (NPs) contribute very little to mass concentrations of PM (which are regulated by policy), they make up the great majority of airborne particle numbers (currently unregulated) (Hansard et al., 2012; Adachi and Buseck, 2010; Múgica-Alvarez et al., 2012; Rönkkö et al., 2017). At the roadside, volatile and semi-volatile organic carbonaceous aerosols derived from vehicle combustion dominate particle number concentrations (Rönkkö et al., 2017). Iron-rich, strongly magnetic combustion- and friction-derived nanoparticles (CFDNPs) contribute a substantial fraction ( $10 \%)$ of the solid (non-volatile) NPs. In addition to industrial point sources, vehicle exhaust and brake wear release iron- and other metal-bearing NPs in abundance (e.g. $4 \times 10^{8}$ magnetic nanoparticles $/ \mathrm{m}^{3}$ air) at the roadside (Maher et al., 2016). The roadside Fe-rich NPs exhibit primary particle sizes ranging from $<10$ to $>100 \mathrm{~nm}$ (Sanderson et al., 2016). These Fe-rich, traffic-derived CFDNPs display a range of undesirable characteristics including surface charge, high redox activity, association with transition metals and carcinogenic organic compounds, and strongly magnetic behavior, all likely to activate critical pathways for cellular and organ damage, including the heart and brain (Maher et al., 2016; Villarreal-Calderon et al., 2012a,2013; Calderón-Garcidueñas et al., 2018). Our previous studies have identified magnetic CFDNPs in 4 
the brains of Metropolitan Mexico City (MMC) residents of all ages (Maher et al., 2016) concomitant with Alzheimer's pathology starting at age 11 months (Calderón-Garcidueñas et al., 2018).

In vitro, the direct inflammatory potential of magnetic iron oxide NPs on human aortic endothelial cells (HAECs) has been demonstrated; phagocytosis and dissolution of these NPs by monocytes were found to provoke oxidative stress and mediate severe endothelial toxicity (Zhu et al., 2011). The development of NPs, including supposedly inert iron oxide NPs, for nanomedicine also provides information regarding their cellular uptake, biodistribution, metabolism and cytotoxicity (Bao et al., 2016). Worryingly, from an air pollution viewpoint, the inhalation of NPs is so effective that it is a preferred route for NP drug delivery (Bao et al., 2016). Synthetic NPs have been shown to be very effective in targeting endothelial cells and critical organelles like mitochondria (Lundy et al., 2016; Wang et al., 2018).

In Mexico City, residents are exposed year-round to airborne PM concentrations above the National Air Ambient Quality Standards for the United States (Calderón-Garcidueñas et al., 2018). Both the $\mathrm{PM}_{2.5}$ annual air quality standard of $12 \mu \mathrm{g} / \mathrm{m}^{3}$ and the $24-\mathrm{hr}$ standard of $35 \mu \mathrm{g} / \mathrm{m}^{3}$ have been exceeded for the last two decades (Querol et al., 2008). Mexico City's nearly 25 million inhabitants, over 50,000 industries, and 5.5 million vehicles consume more than 40 million liters of petroleum fuels per day. Metal-bearing NPs are abundant in Mexico City air. More than $60 \%$ of such NPs, collected and analyzed $(\mathrm{n}=572)$ by transmission electron microscopy, contain $\mathrm{Fe}, \mathrm{Pb}$ or $\mathrm{Zn}$ (Figure 1) (Adachi and Buseck, 2010).

Solid CFDNPs in air pollution are characterized by the abundant presence of strongly magnetic, iron-rich particles, which condense and/or oxidize upon airborne release, often retaining a 
rounded or spherical shape as they cool. These magnetic 'nanospheres' comprise a ubiquitous and abundant component of the urban airborne PM mix (Hansard et al., 2012; Adachi and Buseck, 2010; Múgica-Alvarez et al., 2012; Maher et al., 2016). Such Fe-bearing pollution particles are released from a wide range of PM sources, including transport (road exhaust and brake-wear, rail and metro), metal processing and power generation plants (Hansard et al., 2012; Múgica-Alvarez et al., 2012).

In southwest MMC, excess concentrations of $\mathrm{PM}_{2.5}$ and PM-LPS (lipopolysaccharides) are the rule while in the northwest, concentrations of $\mathrm{PM}_{2.5}$ and $\mathrm{PM}$-associated metals are higher. These spatial pollution differences are reflected by differential responses of heart inflammatory genes in mice exposed for 16 months to ambient air (Villarreal-Calderon et al., 2012b). Gene mRNA myocardial expression for interleukin- $1 \beta$ (IL-1 $\beta)$, tumor necrosis factor- $\alpha$ (TNF- $\alpha)$, and cyclooxygenase-2 (COX2) was up-regulated in mice exposed to SW and NW air; the LPS receptor CD14 (cluster of differentiation antigen 14) was additionally up-regulated in the SWexposed mice (Villarreal-Calderon et al., 2012b). Myocardial inflammatory gene expression in right and left ventricles of 21 children and young adults ages $18.5 \pm 2.6 \mathrm{y}$, also differs in SW v NW MMC areas (Villarreal-Calderon et al., 2012a). For the SW (high PM-LPS) residents, right ventricles had significant up-regulation of 29 of 84 inflammasome genes, including NLRC1, NLRC3 and NOD factors and caspases (Villarreal-Calderon et al., 2012a). These previous findings indicate the potential for cardiac damage even in young urbanites (Villarreal-Calderon et al., 2012a).

Our first aim was to investigate if magnetic CFDNPs, abundant in airborne particulate pollution, are present in myocardium, and, if so, to identify their composition and concentrations. The 
targeted cohort, 72 children and young adults with sudden deaths (MMC n: 63), has previously been investigated with regard to identification and staging of Alzheimer pathology, using AT8 hyperphosphorylated tau and 4G8 (amyloid $\beta$ 17-24) (Calderón-Garcidueñas et al., 2018). Each of the sixty-three MMC subjects showed cortical tau pre-tangles, neurofibrillary tangles (NFT) Stages I-V and amyloid in phases 1-4 (Calderón-Garcidueñas et al., 2018).

We used magnetic analyses and electron microscopy (TEM) to identify and quantify heart NPs that were consistent, in their size, morphology and composition, with magnetic nanospheres formed as CFDNPs. The second aim was to investigate the myocardial location of CFDNPs in critical organelles including mitochondria, ER and mitochondria-endoplasmic reticulum contact sites (MERCs). TEM investigation of myocardium pathology was additionally achieved by examining young dogs exposed to cleaner air versus the MMC atmosphere.

The normal cellular isoform of the prion protein $\left(\mathrm{PrP}^{\mathrm{C}}\right)$ is widely distributed in the central nervous system (CNS) and in diverse extra-CNS tissues including the myocardium (Zanetti et al., 2014). $\operatorname{PrP}^{\mathrm{C}}$ has a key role in the protective adaptive response against oxidative stress, as suggested by the increased $\operatorname{PrP}^{\mathrm{C}}$ expression post-ischemic reperfusion (Zanetti et al., 2014). We investigated $\mathrm{PrP}^{\mathrm{C}}$ in the myocardium of young residents, given its role in countering oxidative stress and hence in 'cardioprotection' (Villarreal-Calderon et al., 2013; Zanetti et al., 2014). Given the potential for anthropogenic NPs high redox capacity, we measured $\mathrm{PrP}^{\mathrm{C}} \mathrm{mRNA}$ expression in biventricular samples MMC vs controls. Endoplasmic reticulum (ER) chaperones, originally identified as glucose depletion-inducible proteins and protein foldases, are increasingly recognized as major regulators of cellular homeostasis, with unexpected roles beyond the ER compartment (Tsai et al., 2018). ER stress induces the expression of ER 
chaperones to manage ER protein quality control (ER-PQC) and actively promotes their relocation to the cell surface (Zhang et al., 2010). This stress-mediated relocalization of ER chaperones is potentially critical for heart cells. Thus, we also investigated the possible impact of CFDNPs on ER stress in young hearts, the relationship between $\operatorname{PrP}^{\mathrm{C}}$ up-regulation and the ER stress marker, glucose regulated protein 78 (GRP78) (Zanetti et al., 2014; Tsai et al., 2018; Zhang et al., 2010).

\section{Materials and Methods}

\subsection{Heart Samples}

The Institutional Review Board (IRB) and the Institutional Animal Care and Use Committee Committees of the University of Montana and the Instituto Nacional de Pediatría approved the study. Seventy-two clinically healthy subjects (2F, 7M, age $23 \pm 8.1$ y controls and $9 \mathrm{~F}, 54 \mathrm{M}$, age $24.79 \pm 10.80 y$ MMC) who died suddenly, without chest or head trauma, were included (Supplementary Table 1). Autopsies were performed 3.7 \pm 1.9 hours after death; there was no evidence of gross cardiovascular pathology. All subjects were negative for the Asp299Gly TLR4 polymorphism and were genotyped for Apolipoprotein E alleles (APOE) (Calderón-Garcidueñas et al., 2018). Heart tissues were fixed in $2 \%$ paraformaldehyde and $2 \%$ glutaraldehyde for TEM and also quickly frozen and stored at $-80{ }^{\circ} \mathrm{C}$ for the RT-PCR (Villarreal-Calderon et al., 2012a) and magnetic studies. We also used myocardial tissues, optimally fixed for electron microscopy, from 5 young dogs ( $\leq 5$ years, from an independent longitudinal study), exposed 24/7 to the SW Mexico City atmosphere. Three age-matched dogs from a 'control' city (Veracruz) were also 
examined. Procedures used followed the Use and Care of Laboratory Animals (NIH Pub No.8623).

\subsection{Magnetic Analysis}

Magnetic measurements were made at the Centre for Environmental Magnetism and Paleomagnetism, Lancaster University. To quantify heart magnetic content, we measured with 2 G RAPID cryogenic and JR6 magnetometers, at room and low temperature $(77 \mathrm{~K})$, the saturation magnetic remanence (SIRM) of freeze-dried left ventricle samples. Heart magnetic particles were examined directly by high resolution TEM (HRTEM) analyses of magneticallyextracted particles, after tissue digestion with the proteolytic enzyme, papain (Maher et al., 2016). Analytical steps were designed, and monitored, to preclude any magnetic contamination.

\subsection{Light microscopy and Transmission Electron Microscopy (TEM)}

Paraffin sections $6 \mu \mathrm{m}$ thick were cut and stained with hematoxylin and eosin (H\&E). Light microscopy and ultrastructural changes in the heart were assessed by experienced pathologists and electron microscopists (LCG, AGM, RRR), blind to the study group. TEM was performed in 31 age-matched control (n: 4) and (n: 27) human cases and 8 SW MMC and in control dogs. Sections were stained with uranyl acetate and lead citrate and examined with a JEOL JEM-1011 TEM microscope, in order to identify the presence and locations of solid (non-volatile), primary NPs. EM evaluations were made from photomicrographs with final magnifications at 13x, 300x, $25,000 x, 50,000 x$ and $80,000 x$. An average of $1062 \pm 287$ NPs was counted in targeted organelles and cells, comprising mitochondria, myofibers, cardiomyocyte nuclei, endothelium, and red 
blood cells (RBC), in both control and exposed cohorts. NP numbers were counted in 25 micrographs for each cohort, at a magnification of $83,300 \mathrm{x}$, with an area of $34.37 \mu \mathrm{m}^{2}$ in each image.

2.4 Estimation of mRNA Abundance of $P r P^{C}$ and Glucose-Regulated Protein 78 (GRP78) by RT$P C R$

To determine the mRNA expression of $\operatorname{PrP}^{\mathrm{C}}$ and GRP78, total RNA was extracted from the 72 heart samples using Trizol Reagent (InVitrogen Corp) (Villarreal-Calderon et al., 2013).

\section{Statistics}

Statistical analyses were performed using R and the SAS statistical software (v9.0). Student's t tests were used to test for significant differences in selected gene expression, and between left and right ventricles. Linear regression models were used to check for any differences between controls and exposed, after adjusting for age and gender. We performed t-tests to check for any difference between control dogs and exposed Mexico City dogs, and between control humans and exposed MMC humans, in the number of CDFNPs in five different locations: mitochondria; myofibers; cardiomyocyte nuclei; endothelium; and red blood cells.

\section{Results}

3.1 Light Microscopy and TEM findings for heart tissue sections from dogs, children and young adults.

Control hearts exhibited mild variation in nuclear size, intact myofibril structure and unremarkable blood vessels (Figure 2A); NPs were relatively few. In contrast, MMC samples 10 
display abundant NPs ( $\sim 2-10 \mathrm{x}$ more than in control tissue samples), together with cardiomyocytes with abnormal nuclei, fragmented myofibrils, partially degranulated mast cells, endothelial filopodia, and RBC with abundant NPs (Figure 2B-G). Intense luminal and abluminal caveolar activity, with NPs present in endothelial caveolae, were major findings in capillaries and small arterioles (Figure 2D-G).

In MMC hearts, NPs appeared to target specific organelles and structures, including mitochondria, ER, MERCs and intercalated disks. In contrast, in the low pollution controls, myofibers were intact, containing tightly packed, intact mitochondria, with oriented cristae (Figure 3A). In MMC residents, mitochondria were abnormal, with fragmented or missing cristae (Figure 3B-E). Electron-dense, rounded NPs, ranging in size from 10 to $70 \mathrm{~nm}$, were observed attached to abnormal cristae, in the midst of the electron lucent matrix (Figure 3B-D, H-J) (Supplementary Figure 1). Similar, rounded NPs were identified in relation to myofibrils and intercalated disks (Figure 3E). Dilated smooth ER structures were common; MERCs were abnormal with numerous ER NPs (Figure 3F, G). Myocardial fibers were disordered and mitochondria exhibited abnormal cristae with NPs inside the matrix in children as young as age 3 (Figure 3H, I) and in adults (Figure 3J). Lipofuscin formation in association with the NPs and in close relationship with abnormal mitochondria was common (Figure 3K). NPs were also seen in close association with heterochromatin and the nuclear envelope (Figure 3L), and in mast cells attached to secretory granules (Figure 3M). Most NPs in the human hearts were located in myofibers. In humans, NPs were common in nuclei in close relationship with heterochromatin. In contrast, dogs had fewer NPs in cardiomyocyte nuclei. 
It is a non-trivial challenge but given the abundance of NPs observed in these tissues, and their co-association with damage to key organelles, we are currently developing new methods to achieve compositional and mineralogical analyses of the NPs in situ, in order to unravel their structure and composition.

\subsubsection{Magnetite nanoparticles}

For the sample-destructive examination of heart NPs, magnetic NPs were separated from the left ventricle of a 48y old East MMC male (ID\#210 in Suppl. Table 1) and analyzed using HRTEM (Figure 4). The magnetic NPs ranged in size from $\sim 5$ to $80 \mathrm{~nm}$; the largest NP observed displayed the presence of fused surface crystallites (Figure 4A), typical of metal-rich pollution particles formed as high-temperature $\left(100 \mathrm{~s}^{\circ} \mathrm{C}\right)$ 'droplets' (Figures 1 and 4B), which then cooled and crystallized upon emission into the urban atmosphere (Maher et al., 2016).

The lattice spacings of individual heart NPs identify them as highly crystalline magnetite and/or maghemite (Figure 4A, E). Fast Fourier transform analysis (Figure 4F, G) of aggregated NPs with smaller particle size ( $8-10 \mathrm{~nm}$ in diameter) also indicates magnetite/maghemite compositions. An aggregate of magnetite/maghemite NPs appears to show some helicoidal superstructure (Figure 4H).

\subsubsection{Quantification of magnetite NP numbers in ventricular (and frontal) tissues}

The magnetic content of the left ventricle samples was quantified by measuring their saturation remanent magnetization (SIRM) at low temperature $(77 \mathrm{~K})$. At this temperature, all the strongly magnetic particles in the tissue samples of $\sim 15 \mathrm{~nm}$ and larger become magnetized and 
measurable (smaller magnetic particles will not contribute to the measured SIRM because their magnetic moments are constantly randomized through thermal agitation). Critically, measurement of the SIRM enables quantitative estimation of the concentration and number of magnetite particles in the bulk tissue samples. Compared to control human and dog samples, the left ventricle MMC samples display variable but often greater magnetite NP concentrations (Table 1). Magnetite particle concentrations ranged from $\sim 0.2$ to $1.7 \mu \mathrm{g} / \mathrm{g}$ ventricular tissue in the exposed cases; equating to particle numbers from a minimum of $\sim 2$ billion to a maximum of 22 billion NPs/g of freeze-dried tissue. Notably, these estimates of magnetite NP concentrations and numbers are conservative, since they do not capture those magnetic NPs which are too small $(<\sim 15 \mathrm{~nm})$ to contribute to the magnetic remanence measured at $77 \mathrm{~K}$.

\subsubsection{Real-time PCR analysis of target genes}

Left ventricle MMC samples had strong up-regulation of $\operatorname{PrP}^{\mathrm{C}}$ compared with controls $(p=0.0003)$ after adjusting for age and gender. Right and left ventricles in MMC subjects showed strong up-regulation of GRP78 vs. controls $(\mathrm{p}<0.0002)$ (Table 2$)$. We found a significant correlation between $\operatorname{PrP}^{\mathrm{C}}$ and GRP78 in left $(\mathrm{p}<0.0001)$ and right ventricles $(\mathrm{p}=0.0055)$ after adjusting for age, gender, APOE and residency.

\section{Discussion}

Strongly magnetic NPs, strikingly similar to the magnetic CFDNPs which are abundant in the urban atmosphere, especially at major roadsides, occur in abundance in young urbanites' hearts. The prolific presence of such iron-rich NPs in cardiac cells might need to be considered as a 
serious public health concern. Consisting of highly-crystalline magnetite and/or maghemite, these externally-derived pollutant particles, likely to be associated both with transition metals (Maher et al., 2016) and PAHs (Halsall et al., 2008) are transported into the heart via inhalation, with subsequent transfer into the circulation and thence into myocardial endothelial cells and cardiomyocytes. Inhalation is a rapid and effective portal of entry of environmental NPs. Inhaled NPs reach the alveolar surface, cross the alveolar/capillary barrier and reach the systemic circulation. At the alveolar/capillary barrier, NPs are capable of hitchhiking red or white blood cells and can reach any organ, including the heart (Figure 2G). In the context of NP therapy development, it is a common observation that transportation of NPs through red blood cells (RBC) boosts delivery of nanocarriers (Brenner et al. 2018). Nanocarriers 'hitchhiking' on RBC by adsorbing onto the $\mathrm{RBC}$ are reported inside endothelial cells in lung capillaries and also in intravascular leukocytes (Brenner et al. 2018). Thus, the RBC/WBC hitchhiking mechanism may be a key delivery platform for CFDNPs to the brain and heart (Calderón-Garcidueñas et al., 2007).

The health impacts of $\sim 22$ billion strongly magnetic NPs/g of ventricular tissue are likely to reflect the combination of surface charge, ferrimagnetism, and redox activity displayed by such NPs, and includes their potential for disruption of the heart's electrical impulse pathways, and hyperthermia and alignment and/or rotation in response to magnetic fields. The cellular and molecular mechanisms leading to the onset of cardiac dysfunction associated with high exposures to particulate matter, and specifically to these iron-rich NPs, may share a common denominator: oxidative stress and the resulting signaling cascades, leading to direct and indirect effects on cardiac structure and function (Lucking et al., 2008; Brook et al., 2010; Mills et al., 2011; Zanetti et al., 2014; Lundy et al., 2016; Nemmar et al., 2016; Heusch,2017; Rajagopalan et 14 
al., 2018). An extra concern in airborne PM is the strong co-association between the concentrations of magnetite/maghemite and particle-bound polyaromatic hydrocarbons (PAHs), especially benzo $[a]$ pyrene (a known carcinogen), a high molecular weight PAH, formed during combustion (Halsall et al., 2008).

Cardiac mitochondria and ER are critical for optimal muscle performance; an intact endothelium is essential. The presence of solid NPs inside key myocardial and endothelial organelles (including mitochondria) and structures (including intercalated disks), which deal directly with the utilization of metabolic fuels, conduction system performance, and intercellular communication will likely impact heart homeostasis (Heusch, 2017; Tirziu et al., 2010).

The high capacity specifically of iron-rich NPs to produce cardiac oxidative stress and DNA damage, and the impact of NP size and cytotoxicity have been demonstrated in a mouse model and in vitro, respectively (Nemmar et al., 2016; Xie et al., 2016). Our data show variable but often greater numbers of NPs and, specifically of magnetite NPs, in exposed subjects versus controls. Both myofibers and mitochondria appear to be targets for NPs. Mitochondria containing rounded, electron dense NPs mostly in the range of 10-30 nm are characterized by altered membrane architecture and abnormal MERCs. Young individuals - clinically healthy before their unexpected death - display left ventricular up-regulation of $\operatorname{PrP}^{\mathrm{C}}$, and biventricular up-regulation of GRP78, associated with activation of the ER stress-signaling pathway. Given the high levels of $\operatorname{PrP}^{\mathrm{C}}$ in the left ventricles of MMC children and young adults, two outcomes can result; either cardiomyocytes can cope with the stress and restore normal cellular functions, or they will undergo apoptosis. Apoptosis is a particularly undesirable response in myocardial tissues, already subjected to significant ventricular inflammation and inflammasome activation 
(Villarreal-Calderon et al., 2012a). The left ventricular $\operatorname{PrP}^{\mathrm{C}}$ up-regulation is likely a temporary protective mechanism for a critical pump chamber.

The issue of ER stress and pathology, seen even in the youngest, 3 y old child, is critical. Smooth ER is a prime site for lipid biosynthesis, a pivot for detoxification enzyme activity and of prime importance for the heart, as a reservoir for calcium cations $\left(\mathrm{Ca}^{2+}\right)$. ER stress is associated with redox activity, deregulated $\mathrm{Ca}^{2+}$ concentrations, and chaperone binding, preventing secretion from the ER of incompletely folded proteins (Song et al., 2017). Failure to execute the careful control processes, of transmembrane stabilization, recruitment of folding factors and protection of folding intermediates from recognition and degradation by the ER control machinery, results in signaling mechanisms such as the unfolded protein responses (UPR) associated with autophagy and apoptosis (Song et al., 2017). The mitochondrial apoptotic pathway is directly linked to ER stress-induced cell death.

The presence of dilated, degenerating ER, abundant NPs in abnormal ER and mitochondria and their association with phagolysosomes and lipofuscin suggest that autophagy was already at work in these young individuals. Repeated exposures to airborne NPs may result in stress (which) is excessive or sustained, (such that) ER function cannot be restored, the UPR triggers apoptosis, thereby removing the affected cell (König et al., 2017). Mitochondria have a critical role in the local $\mathrm{Ca}^{2+}$ control. Alteration in calcium signaling mechanisms by the CFDNPs may thus be of key myocardial and vascular importance (Holme et al., 2019).

Our findings in seemingly healthy children and young adults newly identify important mechanistic pathways to explain the higher risk of $\mathrm{CV}$ disease in susceptible, high pollutionexposed urban populations. Understanding of the adaptive and maladaptive ER-PQC and UPR 16 
myocardial responses is critical for 'cardioprotection' of such vulnerable, exposed individuals (Heusch, 2017). Cardioprotection is defined here as interventions to prevent the early, evolving damage seen in these exposed, young "healthy" individuals, rather than waiting for subsequent development of an acute myocardial infarction or having CV surgery. Policies designed to reduce exposure to airborne PM substantially, together with, for example, diet-targeted interventions starting in childhood (Lim et al., 2019), can be key players in cardioprotection and $\mathrm{CV}$ disease prevention.

Magnetite CFDNPs transported to the heart are likely to be co-associated both with other redoxactive and toxic metals (e.g. $\mathrm{Cu}$ ) and surface-adsorbed species (Halsall et al., 2008). Hence, their potential bioreactivity will far exceed the surface-coated Fe oxide NPs studied in theranostic contexts. Furthermore, the strongly magnetic CFDNPs observed here can respond to external magnetic fields and may be involved both in heart electrical dysfunction and cell damage whether by magnetic rotation or hyperthermia.

Cardiovascular, genetic, environmental and lifestyle-associated risk factors are increasingly recognized as important for Alzheimer's disease pathogenesis (de Bruijn and Ikram, 2014; Broce et al., 2018). Mexico City residents experience high pre- and post-natal exposures to both solid and semi-volatile CFDNPs, PAHs and endotoxins. In the case of the young Mexico City individuals included here, all 63 individuals had magnetic CFDNPs associated with early and progressive damage to the neurovascular unit, and evolving Alzheimer's pathology starting in the brainstem in young children (Calderón-Garcidueñas et al., 2018). It is remarkable to report that mild cognitive impairment and dementia scores are present in $55 \%$ of seemingly healthy Mexican young adults residing in cities with concentrations of fine particulate matter above the 
USEPA standard (Calderón-Garcidueñas et al., 2019). It seems likely that the sequence of oxidative stress, ER stress and chronic inflammation leading to an increase in $\mathrm{CV}$ disease risk (Brook et al., 2010; Rajagopalan et al., 2018), could apply equally to Alzheimer's disease. Thus, chronic exposure to air pollution NPs, whether sourced from heavily-trafficked roads, industry, or power generation plants, may be the causal link between increased incidence both of CVD and $\mathrm{AD}$.

Critical gaps remain in our knowledge and understanding of the relationships between particulate air pollution and CVD. So far, pollution data exist for airborne $\mathrm{PM}_{2.5}$ (regulated and measured) but not for the concentrations, sizes and chemical profiles of ultrafine PM (unregulated and unmeasured). In terms of the mechanistic pathways by which exposures contribute to CVD development, we need to address the complex interactions associated with the biodistribution and bioavailability of inhaled, solid CFDNPs, the nature of the biomolecular corona, their internalization into cells and organelles, and the multiple impacts of their charge, size, composition, and, for magnetic CFDNPs, their magnetic properties and their cellular effects. The biological basis for the interactive effects of CFDNPs and right and left ventricles and auricles is another potentially important area; what, for example, is the impact of radiofrequency radiation in young populations with hearts and brains containing $\sim 10^{9} / \mathrm{g}$ magnetisable CFDNPs?

\section{Conclusions}

Magnetic CFDNPs were identified as highly abundant in left ventricular samples from young subjects lifelong exposed to high concentrations of particulate air pollution above current USEPA standards. The organelles and structures containing abundant NPs displayed substantial abnormality. The integrity of ER and mitochondria is critical for proper protein quality control; 
improbable in light of repeated/sustained cardiac ER stress and inflammation. Notwithstanding their youth, these subjects also have significant neurovascular unit damage and evolving Alzheimer's disease. These findings indicate the significance of the role of early mitochondrial damage, associated with the abundant presence of NPs in the range of $10-30 \mathrm{~nm}$ in diameter, and ER stress in the initiation and progression of cardiac and vascular dysfunction; and hence the need for early cardioprotection interventions. Failure to compensate for chronic myocardial inflammation, oxidative and ER stress possibly resulting from incursion of iron-rich, magnetic, redox-active NPs may prime the development of pathophysiological CV states in children and young adults in polluted environments. Identification of magnetic CFDNPs in the heart tissue of children and young adults provides an important novel layer of information for the understanding of CVD pathogenesis and emphasizes the urgent need for prioritization of particulate air pollution control. Exposure to iron-rich combustion- and friction-derived nanoparticles is a modifiable risk factor for the development of cardiovascular diseases. This study substantially advances the case for global efforts to reduce exposure to particulate matter air pollution and, specifically, to regulate the ultrafine fraction.

\section{Contributors}

LCG, CGC, JVC, AGM, and RRR study concept and design, analysis and interpretation of molecular biology, pathology and electron microscopy data, writing, drafting and revising the manuscript, study supervision and coordination. PSM did the statistical analysis, writing, drafting and revising the manuscript. RTJ analysis and interpretation of pollutant data, writing the pollution section. BAM, VVK and IAMA carried out the magnetic and HRTEM analyses, 
and BAM contributed to writing and revising the manuscript. BPG was in charge of the veterinarian care and revised the manuscript.

Acknowledgments: Donald MacLaren (Physics Department, University of Glasgow) kindly assisted with the HRTEM analysis.

\section{References}

Adachi K, Buseck PR. 2010.Hosted and free-floating metal-bearing atmospheric nanoparticles in Mexico City. Environ Sci Technol 44; 2299-2304, PMID: 20192166

https://pubs.acs.org/doi/10.1021/es902505b

Bao Y, Wen T, Samia ACS, Khandhar A, Krishnan KM. 2016. Magnetic Nanoparticles: Material Engineering and Emerging Applications in Lithography and Biomedicine. J Mater Sci. 51: 513553. PMID: 26586919 https://link.springer.com/article/10.1007\%2Fs10853-015-9324-2

Brenner JS, Pan DC, Myerson JW, Marcos-Contreras OA, Villa CH, Patel P, Hekierski H, Chatterjee S, Tao JQ, Parhiz H, Bhamidipati K, Uhler TG, Hood ED, Kiseleva RY, Shuvaev VS, Shuvaeva T, Khoshnejad M, Johnston I, Gregory JV, Lahann J, Wang T, Cantu E, Armstead WM, Mitragotri S, Muzykantov V (2018). Red blood cell-hitchhiking boosts delivery of nanocarriers to chosen organs by orders of magnitude. Nat Commun. 9(1):2684. doi: 10.1038/s41467-018-05079-7. 
Broce IJ, Tan CH, Fan CC, Jansen I, Savage JE, Witoelar A, Wen N, Hess CP, Dillon WP, Glastonbury CM, Glymour M, Yokoyama JS, Elahi FM, Rabinovici GD, Miller BL, Mormino EC, Sperling RA, Bennett DA, McEvoy LK, Brewer JB, Feldman HH, Hyman BT, PericakVance M, Haines JL, Farrer LA, Mayeux R, Schellenberg GD, Yaffe K, Sugrue LP, Dale AM, Posthuma D, Andreassen OA, Karch CM, Desikan RS.2018. Dissecting the genetic relationship between cardiovascular risk factors and Alzheimer's disease. Acta Neuropathol. doi:

10.1007/s00401-018-1928-6. PMID: 30413934

https://ink.springer.com/article/10.1007\%2Fs00401-018-1928-6

Brook RD, Rajagopalan S, Pope CA, 3rd, Brook JR, Bhatnagar A, Diez-Roux AV, Holguin F, Hong Y, Luepker RV, Mittleman MA, Peters A, Siscovick D, Smith SC Jr, Whitsel L, Kaufman JD; American Heart Association Council on Epidemiology and Prevention, Council on the Kidney in Cardiovascular Disease, and Council on Nutrition, Physical Activity and Metabolism.2010. Particulate matter air pollution and cardiovascular disease: an update to the scientific statement from the American Heart Association. Circulation. 121: 2331-78. PMID: 20458016 https://www.ahajournals.org/doi/10.1161/CIR.0b013e3181dbece1

Calderón-Garcidueñas L, Franco-Lira M, Torres-Jardón R, Henriquez-Roldán C, Barragán-Mejía G, Valencia-Salazar G, González-Maciel A, Reynoso-Robles R, Villarreal-Calderón R, Reed W(2007). Pediatric respiratory and systemic effects of chronic air pollution exposure: nose, lung, heart, and brain pathology. Toxicol Pathol. 35:154-62.

Calderón-Garcidueñas L, Gónzalez-Maciel A, Reynoso-Robles R, Delgado-Chávez R, Mukherjee PS, Kulesza RJ, Torres-Jardón R, Ávila-Ramírez J, Villarreal-Ríos R.2018. Hallmarks of Alzheimer disease are evolving relentlessly in Metropolitan infants, children and 21 
young adults. APOE4 carriers have higher suicide risk and higher odds of reaching NFT stage V at $\leq 40$ years of age. Environ Res. 164: 475-87 PMID: 29587223 https://www.sciencedirect.com/science/article/pii/S0013935118301439?via\%3Dihub

Calderón-Garcidueñas L, Mukherjee PS, Kulesza RJ, Torres-Jardón R, Hernández-Luna J, Ávila-Cervantes R, Macías-Escobedo E, González-González O, González-Maciel A, GarcíaHernández K, Hernández-Castillo A, Villarreal-Ríos R; UVM Group Research (2019). Mild cognitive impairment and dementia involving multiple cognitive domains in Mexican urbanites.

J Alzheimers Dis. PMID: 30909241

https://www.ncbi.nlm.nih.gov/sites/entrez?term...\%20JAD\%22\%5BJournal\%5D

De Bruijn RF, Ikram MA (2014). Cardiovascular risk factors and future risk of Alzheimer's disease. BMC Med 12:130 PMID: 25385322 https://bmcmedicine.biomedcentral.com/articles/10.1186/s12916-014-0130-5

Dockery DW, Pope CA, III, Xu X, Spengler JD, Ware JH, Fay ME, Ferris BG, Speizer FE. 1993. An association between air pollution and mortality in six U.S. cities. N Engl J Med. 329:1753-1759. PMID: 8179653

https://www.nejm.org/doi/full/10.1056/NEJM199312093292401

Halsall CJ, Maher BA, Karloukovski VV, Shah P, Watkins SJ.2008. A novel approach to investigating indoor/outdoor pollution links: Combined magnetic and PAH measurements. Atmospheric Environment 42: 8902-8909. https://www.sciencedirect.com/science/article/pii/S1352231008008054?via\%3Dihub 
Hansard R, Maher BA, Kinnersley RP.2012. Rapid magnetic biomonitoring and differentiation of atmospheric particulate pollutants at the roadside and around two major sites in the UK. Environ Sci Technol 46:4403-4410 https://pubs.acs.org/doi/10.1021/es203275r

Heusch G. 2017.Critical issues for the translation of cardioprotection. Circ Res. 120:1477-1486. PMID: 28450365 https://www.ahajournals.org/doi/10.1161/CIRCRESAHA.117.310820 Holme JA, Brinchmann BC, Le Ferrec E, Lagadic-Gossmann D, Øvrevik J(2019). Combustion particle-induced changes in calcium homeostasis: A contributing factor to vascular disease? Cardiovasc Toxicol PMID:30955163 https://link.springer.com/article/10.1007\%2Fs12012-019$\underline{09518-9}$

König J, Ott C, Hugo M, Jung T, Bulteau AL, Grune T, Höhn A.2017. Mitochondrial contribution to lipofuscin formation. Redox Biol. 11:673-681. PMID: 28160744 https://www.sciencedirect.com/science/article/pii/S2213231717300423?via\%3Dihub

Lim CC, Hayes RB, Ahn J, Shao J, Silverman DT, Jones RR, Thurston GD (2019).

Mediterranean diet and the association between air pollution and cardiovascular disease mortality risk. Circulation 139:1766-1775, PMID: 30700142 https://www.ahajournals.org/doi/10.1161/CIRCULATIONAHA.118.035742

Lucking AJ, Lundback M, Mills NL, Faratian D, Barath SL, Pourazar J, Cassee FR, Donaldson K, Boon NA, Badimon JJ, Sandstrom T, Blomberg A, Newby DE.2008. Diesel exhaust inhalation increases thrombus formation in man. Eur Heart J. 29:3043-51 PMID: 18952612 https://academic.oup.com/eurheartj/article/29/24/3043/587783 
Lundy DJ, Chen KH, Toh EKW, Hsieh PCH. 2016. Distribution of Systemically Administered Nanoparticles Reveals a Size-Dependent Effect Immediately following Cardiac IschaemiaReperfusion Injury. Sci Rep. 6: 25613. doi: 10.1038/srep25613 PMID: 27161857 https://www.nature.com/articles/srep25613

Maher BA, Ahmed IA, Karloukovski V, MacLaren DA, Foulds PG, Allsop D, Mann DM, Torres-Jardón R, Calderón-Garcidueñas L. 2016. Magnetite pollution nanoparticles in the human brain. Proc Natl Acad Sci U S A. 113:10797-801. PMID: 27601646 https://www.pnas.org/content/113/39/10797

Maher, B.A. 1988. Magnetic properties of some synthetic sub-micron magnetites, Geophysical Journal International, 94, 83-96, https://doi.org/10.1111/j.1365-246X.1988.tb03429.x

Malik AO, Jones PG, Chan PS, Peri-Okonny PA, Hejjaji V, Spertus JA.2019. Association of long-term exposure to particulate matter and ozone with health status and mortality in patients after myocardial infarction. Circ Cardiovasc Qual Outcomes 12(4):e005598. doi:

10.1161/CIRCOUTCOMES. 119.005598

https://www.ahajournals.org/doi/10.1161/CIRCOUTCOMES.119.005598

Mills NL, Miller MR, Lucking AJ, Beveridge J, Flint L, Boere AJ, Fokkens PH, Boon NA, Sandstrom T, Blomberg A, Duffin R, Donaldson K, Hadoke PW, Cassee FR, Newby DE. 2011. Combustion-derived nanoparticulate induces the adverse vascular effects of diesel exhaust inhalation. Eur Heart J. 32:2660-71 PMID: 21753226

https://academic.oup.com/eurheartj/article/32/21/2660/441849 
Múgica-Alvarez V, Figueroa-Lara J, Romero-Romo M, Sepúlveda- Sanchez J, Lopez-Moreno T. 2012. Concentrations and properties of airborne particles in the subway system. Atmospheric Environment 49: 284-293 http://www.nal.usda.gov/

Nemmar A, Beegam S, Yuvaraju P, Yasin J, Tariq S, Attoub S, Ali BH. 2016. Ultrasmall superparamagnetic iron oxide nanoparticles acutely promote thrombosis and cardiac oxidative stress and DNA damage in mice. Part Fibre Toxicol. 13(1):22. PMID: 27138375 https://particleandfibretoxicology.biomedcentral.com/articles/10.1186/s12989-016-0132-x

Querol X, Pey J, Minguillón MC, Pérez N, Alastuey A, Viana M, Moreno T, Bernabe RM, Blanco S, Cardenas B, Vega E, Sosa G, Escalona S, Ruiz H, Artiñano B. 2008. PM speciation and sources in Mexico during the MILAGRO-2006 Campaign. Atmos Chem Phys. 8: 111-121 https://doi.org/10.5194/acp-8-111-2008

Rajagopalan S, Al-Kindi SG, Brook RD. 2018. Air pollution and cardiovascular disease. JACC State-of-the-Art Review. J Am Coll Cardiol 72: 2054-70. PMID: 30336830 https://www.sciencedirect.com/science/article/pii/S0735109718383554?via\%3Dihub

Rönkkö T, Kuuluvainen H, Karjalainen P, Keskinen J, Hillamo R, Niemi JV, Pirjola L, Timonen HJ, Saarikoski S, Saukko E, Järvinen A, Silvennoinen H, Rostedt A, Olin M, Yli-Ojanperä J, Nousiainen P, Kousa A, Dal Maso M.2017. Traffic is a major source of atmospheric nanocluster aerosol. Proc Natl Acad Sci U S A. 114:7549-7554. PMID: 28674021 https://www.pnas.org/content/114/29/7549 
Sanderson P, Su SS, Chang ITH, Delgado Saborit JM, Kepaptsoglou DM, Weber RJM, Harrison RM (2016). Characterisation of iron-rich atmospheric submicrometre particles in the roadside environment. Atmospheric Environment 140:167-175

https://doi.org/10.1016/j.atmosenv.2016.05.040

Song S, Tan J, Miao Y, Li M, Zhang Q. 2017. Crosstalk of autophagy and apoptosis:

Involvement of the dual role of autophagy under ER stress. J Cell Physiol. 232:2977-2984.

PMID:28067409 https://onlinelibrary.wiley.com/doi/full/10.1002/jcp.25785

Tibuakuu M, Michos ED, Navas-Acien A, Jones MR.2018.Air pollution and cardiovascular disease: A focus on vulnerable populations worldwide. Curr Epidemiol Rep. 5:370-378. doi: 10.1007/s40471-018-0166-8. https://link.springer.com/article/10.1007\%2Fs40471-018-0166-8

Tirziu D, Giordano FJ, Simons M. 2010. Cell communications in the heart. Circulation. 122:92837. PMID: 20805439

https://www.ahajournals.org/doi/10.1161/CIRCULATIONAHA.108.847731

Tsai YL, Ha DP, Zhao H, Carlos AJ, Wei S, Pun TK, Wu K, Zandi E, Kelly K, Lee AS. 2018. Endoplasmic reticulum stress activates SRC, relocating chaperones to the cell surface where GRP78/CD109 blocks TGF- $\beta$ signaling. Proc Natl Acad Sci USA 115:E4245-E4254. PMID:

29654145 https://www.pnas.org/content/115/18/E4245

Villarreal-Calderon R, Dale G, Delgado-Chávez R, Torres-Jardón R, Zhu H, Herritt L, GónzalezMaciel A, Reynoso-Robles R, Yuan Y, Wang J, Solorio-López E, Medina-Cortina H, CalderónGarcidueñas L. 2012a.Intra-city Differences in Cardiac Expression of Inflammatory Genes and 
Inflammasomes in Young Urbanites: A Pilot Study. J Toxicol Pathol. 25:163-73. PMID:

22907983 https://www.jstage.jst.go.jp/article/tox/25/2/25_2012-0006/_article

Villarreal-Calderon R, Reed W, Keefe S, Herritt L, Brooks D, Torres-Jardón R，Calderón-

Garcidueñas L. 2012b. Urban Air Pollution Produces Up-Regulation of Myocardial

Inflammatory Genes and Dark Chocolate Provides Cardioprotection. Exp Tox Path 64:297- 306

PMID: 20932730

https://www.sciencedirect.com/science/article/pii/S0940299310001545?via\%3Dihub

Villarreal-Calderon R, Franco-Lira M, González-Maciel A, Reynoso-Robles R, Harritt L, Pérez-

Guillé B, Ferreira-Azevedo L, Drecktrah D, Zhu H, Sun Q, Torres-Jardón R, Aragón-Flores M,

Calderón-Garcidueñas A, Diaz P, Calderón-Garcidueñas L. 2013.Up-regulation of mRNA

ventricular PRNP prion protein gene expression in air pollution highly exposed young urbanites:

endoplasmic reticulum stress, glucose regulated protein 78, and nanosized particles. Int J Mol Sci.

14: 23471-91. PMID: 24287918 https://www.mdpi.com/1422-0067/14/12/23471

Wang H, Gao Z, Liu X, Agarwal P, Zhao S, Conroy DW, Ji G, Yu J, Jaroniec CP, Liu Z, Lu X, Li X, He X.2018. Targeted production of reactive oxygen species in mitochondria to overcome cancer drug resistance. Nat Commun. 9: 562. doi: 10.1038/s41467-018-02915-8 PMID:

29422620 https://www.nature.com/articles/s41467-018-02915-8

Xie Y, Liu D, Cai C, Chen X, Zhou Y, Wu L, Sun Y, Dai H, Kong X, Liu P.2016. Sizedependent cytotoxicity of Fe3O4 nanoparticles induced by biphasic regulation of oxidative stress in different human hepatoma cells. Int J Nanomedicine. 11:3557-70. PMID: 27536098 
https://www.dovepress.com/size-dependent-cytotoxicity-of-fe3o4-nanoparticles-induced-bybiphasic-peer-reviewed-article-IJN

Zanetti F, Carpi A, Menabò R, Giorgio M, Schulz R, Valen G, Baysa A, Massimino ML, Sorgato MC, Bertoli A, Di Lisa F. 2014. The cellular prion protein counteracts cardiac oxidative stress. Cardiovasc Res. 104:93-102. PMID: 25139744

https://academic.oup.com/cardiovascres/article/104/1/93/319525

Zhang Y, Liu R, Ni M, Gill P, Lee AS.2010. Cell surface relocalization of the endoplasmic reticulum chaperone and unfolded protein response regulator GRP78/BiP. J Biol Chem. 285:15065-15075. PMID: 20208072 http://www.jbc.org/content/285/20/15065

Zhu MT, Wang B, Wang Y, Yuan L, Wang HJ, Wang M, Ouyang H, Chai ZF, Feng WY, Zhao YL.2011. Endothelial dysfunction and inflammation induced by iron oxide nanoparticle exposure: Risk factors for early atherosclerosis. Toxicol Lett. 203:162-71. PMID: 21439359 https://www.sciencedirect.com/science/article/pii/S0378427411001202?via\%3Dihub 


\section{FIGURES}

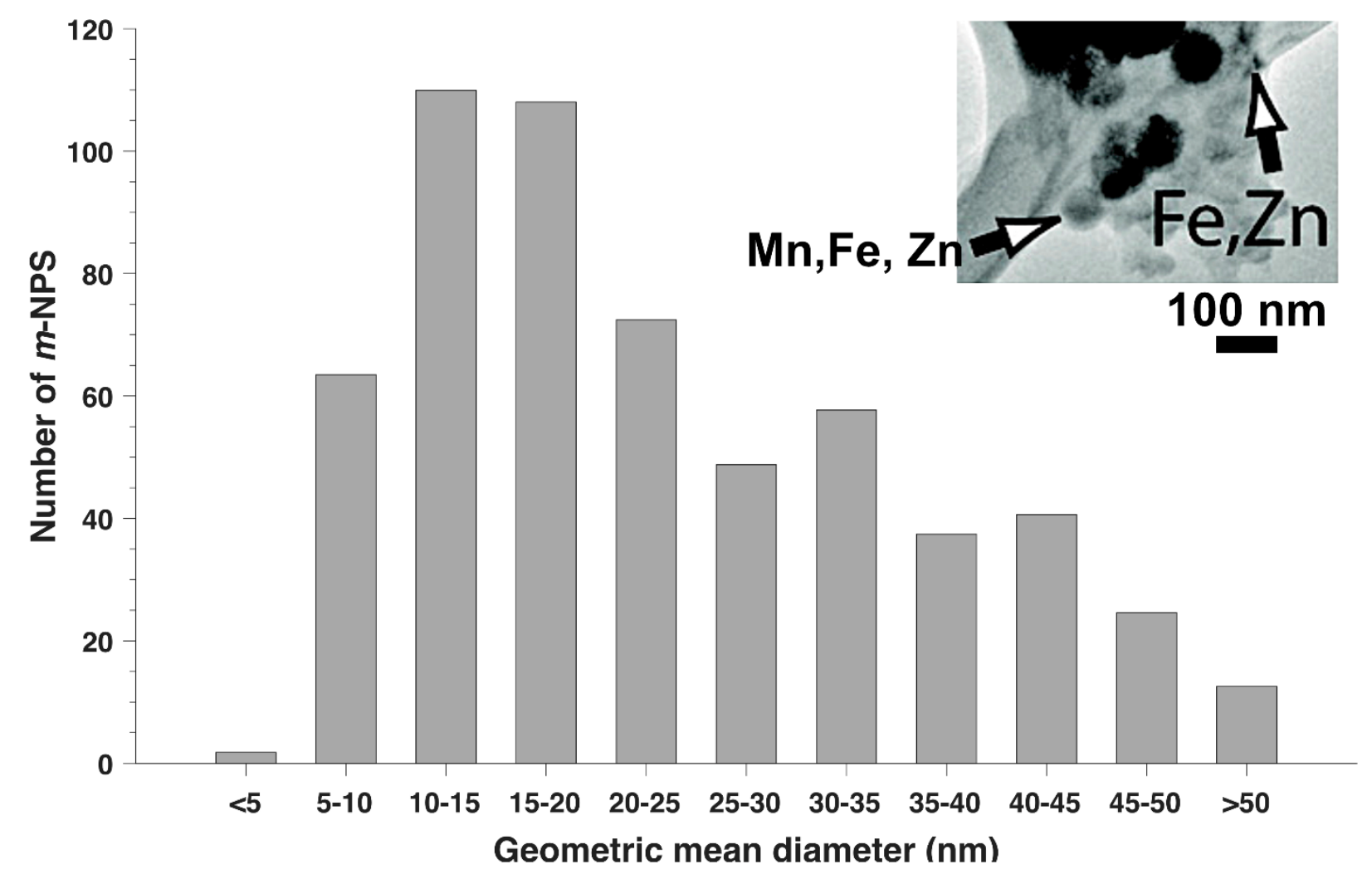

Figure 1. The particle size distribution of metal-bearing NPs samples in Mexico City air; inset transmission electron micrograph shows the typical rounded shape of these pollution 'nanospheres', rich in Fe and other associated transition metals. (Adapted from Adachi and Buseck, 2010). 

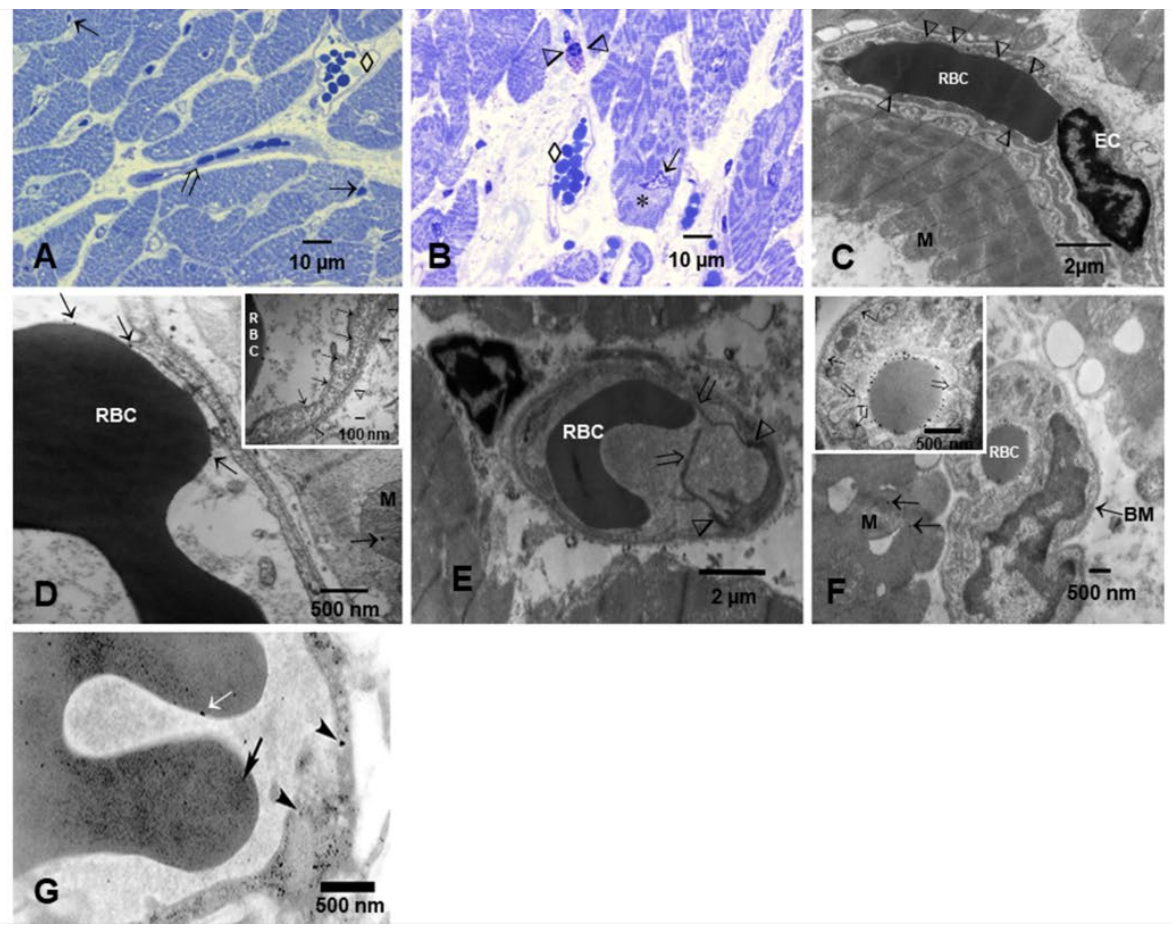

Figure 2. Myocardial blood vessels, light microscopy (A and B) and ultrastructure by TEM (C $\mathrm{G})$ in control (2A) and MMC cases $(2 \mathrm{~B}-2 \mathrm{G})$

2A. Left ventricle capillaries (arrows), venous vessels $(\diamond)$ and arterioles (open arrow) are unremarkable in control samples. Light microscopy, Toluidine blue stain x 100

2B. A partially degranulated mast cell (arrowheads) with clumping of nuclear chromatin is observed in the right ventricle from an 18y old MMC male. Abnormal cardiomyocyte nuclei are seen (arrow) along areas with disrupted myofibrils $(*)$. A venous vessel is unremarkable $(\diamond)$. Light microscopy, Toluidine blue stain x100

2C. One capillary contains one single RBC that occupies the entire lumen and keeps close contact with the endothelial surface (arrow head). The nucleus of the endothelial cell (EC) is unremarkable. Mitochondria (M). Electron micrograph x 10,000

2D. A left ventricle capillary with intense caveolae activity and close contact of the RBC with the endothelium. CFDNPs are seen at contact points (arrows) and in the cardiomyocyte mitochondria (M). The insert shows a section of the same vessel with intense luminal caveolae activity (arrows) and abluminal (arrow head). Electron micrograph x 30000 and insert x 80000

2E. Left ventricle capillary with intense endothelial filopodia formation arising from the tight junctions (arrow head) and extending into the lumen (open arrows). The luminal erythrocyte is marked RBC and contains clusters of CFDNPs. Electron micrograph x 10,000 
2F. A left ventricle capillary shows one RBC loaded with CFDNPs, also seen in the adjacent myofibril in mitochondria (M) and in the midst of the fibrils (arrows). The insert shows intense abluminal caveolae activity (arrows), filopodial projections are present (open arrows) and tight junctions (TJ) are identified. Electron micrograph x 15,000, insert x 50,000

2G. Right ventricular capillary shows intense caveolae activity and CFDNPs inside caveolae (arrow head) and in the RBC (black arrow). The white arrow points to the larger CFDNP on the RBC. Electron micrograph x 30,000
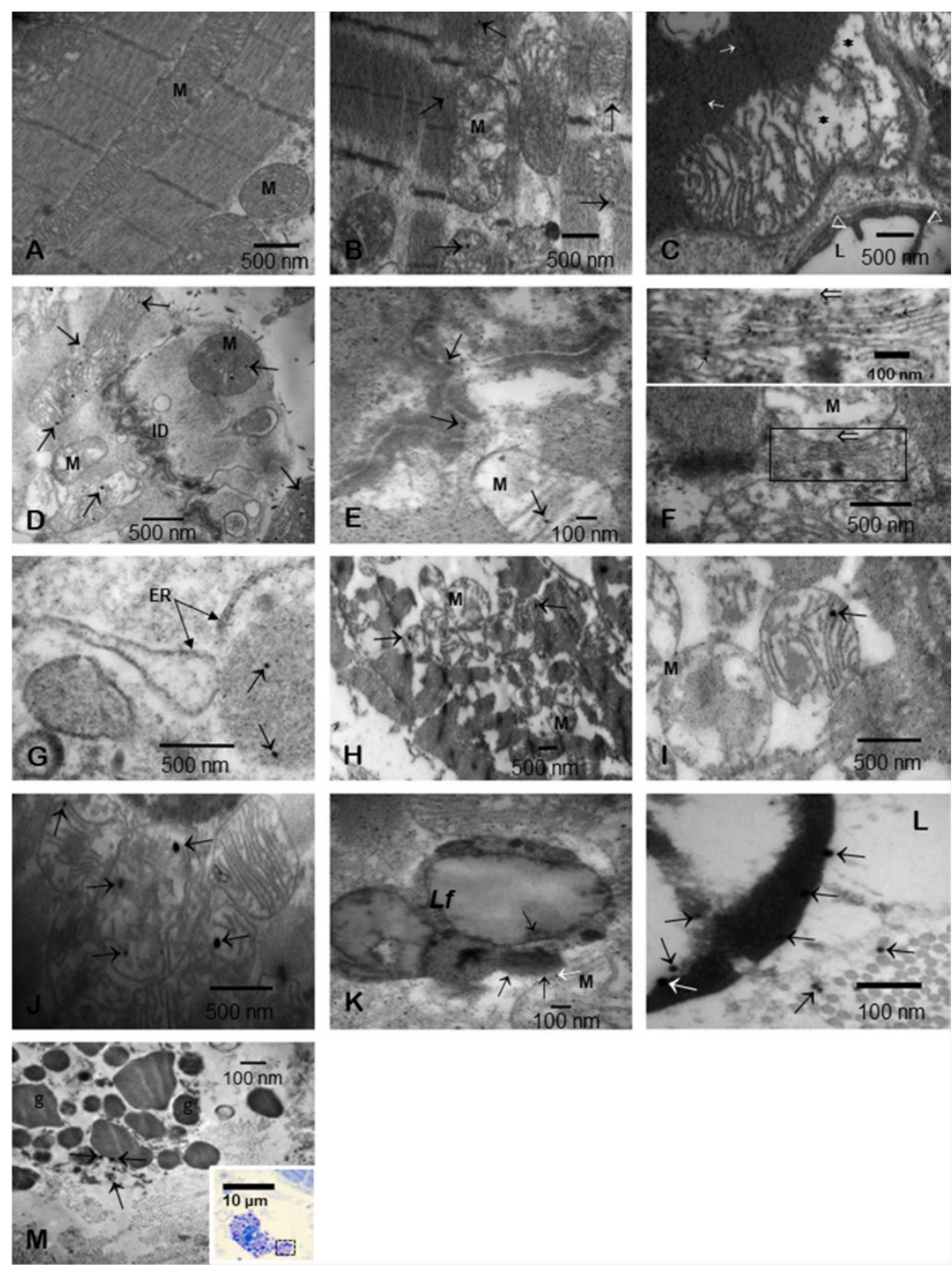
Figure 3. Myocardial ultrastructural changes in low pollution controls (3A) versus MMC residents (3B-3M).

3A. Control left ventricle with unremarkable mitochondria and myofilaments in longitudinal section. Electron micrograph x 30,000

3B. In contrast, this left ventricular section from a Mexico City dog shows significant variation in mitochondrial (M) size and morphology in the longitudinal plane. CFDNPs are seen inside the abnormal mitochondria and in myofibrils (arrows). Electron micrograph x 30,000

3C. An abnormal mitochondrion shows fragmented cristae and spaces devoid of any structure $(*)$. CFDNPs are seen in association with myofibrils (white arrows), arrow heads point to endothelial filopodia and caveolae activity. Electron micrograph x 30,000

3D. Left ventricle sample showing numerous abnormal mitochondria (M) containing CFDNPs inside their abnormal matrixes (arrows). The step-like features of an intercalated disk (ID) are shown. Electron micrograph x 30,000

3E. Higher magnification image of the intercalated disk from Figure 3E. CFDNPs with high electron density are seen within the matrix of the desmosomes (arrows). An adjacent abnormal mitochondrion (M) with one single CFDNP is also seen. Electron micrograph $\mathrm{x} 80,000$

3F. Compound picture showing mitochondria-associated endoplasmic reticulum (MERCs) ultrastructure. The mitochondrion (M) is abnormal, with short, fragmented cristae and the ER exhibits close-ER mitochondrial contact. The upper insert illustrates the relationship between the abnormal mitochondria (open arrow) and the abnormal ER with focal, dilated cisternae with CFDNPs (short arrows). Electron micrograph x 30,000 Insert x 100,000

3G. Abnormal dilated endoplasmic reticulum (ER) and a fragment of ER with CFDNPs. Notice the dilated ER in close contact with an ill-defined structure with two CFDNPs (arrows). Electron micrograph $\mathrm{x} 80,000$

3H. Left ventricle from $3 y$ old boy, with mitochondria containing CFDNPs. This child (ID\#4 in Suppl. Table 1) already displays hyperphosphorylated Tau in his brainstem. Electron micrograph x 5,000

3I. Same 3 year old child as Figure 3I. A close-up of two abnormal mitochondria containing CFDNPs (arrow, right mitochondria) and an ill-defined material in the left mitochondria matrix. Electron micrograph x 50,000

3J. Left ventricle from a 37 y old male (ID\#187 Suppl. Table 1) with several mitochondria containing CFDNPs. Electron micrograph x 50,000

3K. A lipofuscin (Lf) structure $1500 \times 800 \mathrm{~nm}$ with CFDNPs (black arrows) is in closeassociation with abnormal mitochondria (M) containing also CFDNPs (white arrow) in close contact with the Lf structure. A myofibril segment is marked (Myo). Electron micrograph $\mathrm{x}$ 80,000 
3L. A close-up of a cardiomyocyte nucleus with numerous CFDNPs in close contact with heterochromatin (black arrows). NPs are also seen outside the nucleus (two right black arrows). The white arrow points to the larger CFDNPs in contact with heterochromatin. Electron micrograph x 100,000

3M. Mast cell from the left ventricle with secretory granules $(\mathrm{g})$ in close contact with CFDNPs (arrows). The insert shows the corresponding partially degranulated mast cell. Electron micrograph x 20,000. Light microscopy, Toluidine blue stain for the mast cell in the insert x 100 


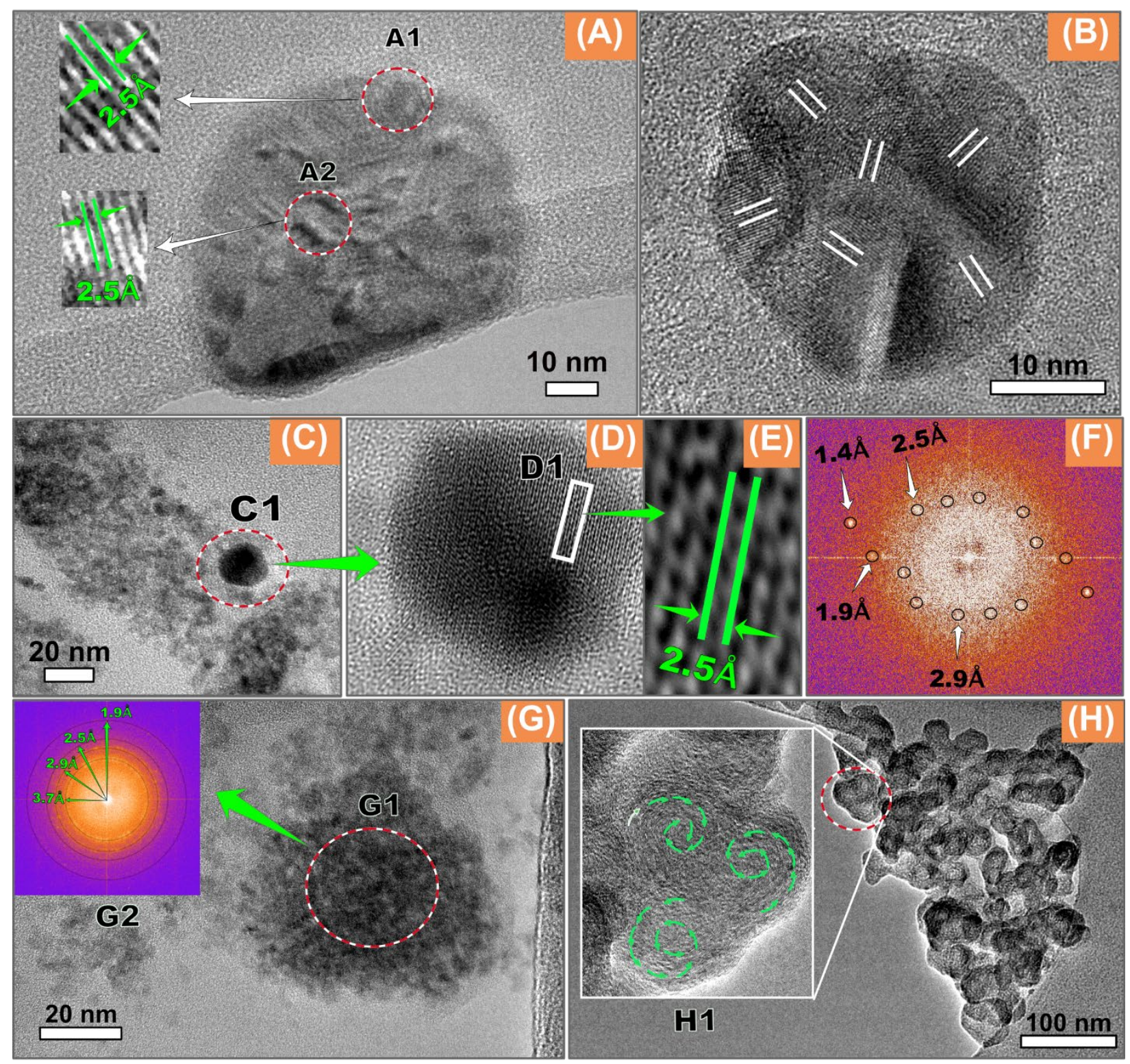

Figure 4 HRTEM micrographs of $(\mathrm{A})$ and $(\mathrm{C}-\mathrm{H})$ magnetic NPs extracted from left ventricle sample in a 48 y old male from East MMC (ID\#210 in Suppl. Table 1), and (b) of an airborne magnetite pollution NP. (A) heart NP of $\sim 80 \mathrm{~nm}$ diameter, with fused interlocking nanocrystallites (note the varying orientations of the individual crystallite faces), with magnetite/maghemite lattice spacing (a1) of $2.5 \AA$; (B) for comparison, airborne pollution particle collected by air sampling near a power generating plant (Didcot, U.K.) consisting of a magnetite nanosphere, with fused, interlocking surface crystallites (note the varying orientations of the individual crystallite faces), typical of high-temperature (e.g. combustion) formation (Maher et al., 2016); (C) aggregated heart nano-magnetite (hkl plane $=311$ ) or nano-maghemite ( hkl plane $=312$ ) particles, with lattice spacing of $2.5 \AA$; (D-F) magnification of selected particle, C1 (shown in (C), with lattice spacing $2.5 \AA$ (D) and its FFT of the (311) or (312) orientation (E); 34 
(G) nanocrystallites (G1) of a mean particle size of $\sim 8 \mathrm{~nm}$, composed of mixed magnetite/maghemite $(\mathrm{G} 2) ;(\mathrm{H})$ magnetic nanoparticles arranged in a striking helical pattern (H1) with a lattice spacing of $4.8 \AA$ A suggesting an orientation in the [113] plane for maghemite (space group: $P 4_{3} 2_{12}$ ) or [111] for magnetite (space group: $F d \overline{3} m$ ). These NPs may have selfassembled, or aggregated during the magnetic extraction process. 


\section{Table 1}

Saturation magnetic remanence, and calculated magnetite concentration and magnetite NP numbers for heart and frontal tissues in controls and Mexico City residents.

\begin{tabular}{|c|c|c|c|c|c|c|c|c|}
\hline Residence & ID & $\begin{array}{c}\text { Age } \\
\text { yr }\end{array}$ & $\begin{array}{c}\text { Sample } \\
\text { mass } \\
(\mathrm{g}) \\
\text { freeze } \\
\text { dried }\end{array}$ & $\begin{array}{c}\text { SIRM } \\
\text { Heart } \\
77 \mathrm{~K} \\
\left(10^{-6}\right. \\
\left.\mathrm{Am}^{2} \mathrm{~kg}^{-1}\right)\end{array}$ & $\begin{array}{l}\text { Magnetite } \\
\text { Left } \\
\text { ventricle } \\
\mu \mathrm{g} / \mathrm{g} \\
\text { dry } \\
\text { tissue* }\end{array}$ & $\begin{array}{c}\text { No. } \\
\text { Magnetite } \\
\text { NPs } \\
10^{9} / \mathrm{g} \mathrm{LV} \\
\text { dry } \\
\text { tissue* }\end{array}$ & $\begin{array}{c}\text { SIRM } \\
\text { Brain } \\
\text { Frontal } \\
77 \mathrm{~K} \\
\left(10^{-6}\right. \\
\left.\mathrm{Am}^{2} \mathrm{~kg}^{-1}\right)\end{array}$ & $\begin{array}{c}\text { Magnetite } \\
\text { concentration } \\
\mu \mathrm{g} / \mathrm{g} \\
\text { Frontal dry } \\
\text { tissue* }\end{array}$ \\
\hline CTL & Human CTL2 & 12 & 0.194 & 6.6 & 0.48 & 5.9 & & \\
\hline CTL & Human CTL6 & 39 & 0.607 & 5.4 & 0.39 & 4.9 & & \\
\hline CTL & & & Ave. & 6.0 & 0.44 & 5.4 & & \\
\hline CTL & Dog CTL3 & & 0.418 & 3.1 & 0.23 & 2.8 & & \\
\hline CTL & Dog CTL4 & & 0.197 & 5.3 & 0.38 & 4.8 & & \\
\hline CTL & Dog CTL6 & & 0.485 & 7.6 & 0.55 & 6.8 & & \\
\hline \multirow[t]{2}{*}{ CTL } & Dog CTL8 & & 0.404 & 1.4 & 0.1 & 1.3 & & \\
\hline & & & Ave. & 4.4 & 0.32 & 3.9 & & \\
\hline \multirow[t]{13}{*}{$\begin{array}{l}\text { Mexico } \\
\text { City } \\
\end{array}$} & Human 122 & 3 & 0.701 & 3.2 & 0.23 & 2.9 & 7.3 & 0.53 \\
\hline & 320 & 16 & 0.251 & 16.8 & 1.22 & 15.1 & 12.4 & 0.9 \\
\hline & 215 & 17 & 0.708 & 5.4 & 0.39 & 4.9 & 7.8 & 0.56 \\
\hline & 205 & 18 & 0.547 & 24.0 & 1.74 & 21.5 & 9.1 & 0.66 \\
\hline & 240 & 20 & 0.299 & 11.6 & 0.84 & 10.4 & 10.5 & 0.76 \\
\hline & 106 & 20 & 0.546 & 5.2 & 0.38 & 4.7 & 12.2 & 0.88 \\
\hline & 234 & 24 & 1.26 & 18.4 & 1.33 & 16.5 & 5.4 & 0.39 \\
\hline & 51 & 25 & 0.805 & 2.8 & 0.2 & 2.5 & 41.3 & 2.99 \\
\hline & 159 & 26 & 0.347 & 9.0 & 0.65 & 8.1 & 17.2 & 1.25 \\
\hline & 319 & 26 & 0.718 & 4.6 & 0.33 & 4.1 & 7.5 & 0.55 \\
\hline & 149 & 27 & 0.498 & 2.6 & 0.19 & 2.3 & 6.6 & 0.48 \\
\hline & & & Ave. & 9.4 & 0.68 & 8.5 & 12.5 & 0.9 \\
\hline & 250 & 48 & 0.258 & 17.6 & 1.28 & 15.8 & 4.0 & 0.29 \\
\hline
\end{tabular}

* Using here an empirically-derived value for SIRMSP/SD magnetite of $13.5 \mathrm{Am}^{2} \mathrm{~kg}^{-1}$, for interacting, mixed single domain (SD) and superparamagnetic (SP) magnetite, of mean particle size $31 \mathrm{~nm}$ (Maher, 1998; Maher et al., 2016), rather than the 'conventional' SIRM magnetite value of $46 \mathrm{Am}^{2} \mathrm{~kg}^{-1}$, which is applicable only to pure, non-interacting, single domain $(50 \mathrm{~nm})$ magnetite particles. For example, Sample 122, from a 3 year old MMC boy has a heart SIRM (77 $\mathrm{K})$ value of $3.2 \times 10^{-6} \mathrm{Am}^{2} \mathrm{~kg}^{-1}$; this value divided by SIRMSP/SD magnetite $\left(13.5 \mathrm{Am}^{2} \mathrm{~kg}^{-1}\right)$ produces a magnetite tissue concentration of $0.23 \mu \mathrm{g} / \mathrm{g}$ dry wt. The number of magnetite particles/g dry tissue can then be estimated by dividing the mass of magnetite (again, per $1 \mathrm{~g}$ dry tissue wt), 0.23 $\mu \mathrm{g}$, by the mass of 1 magnetite particle $\left(8.07224^{-11} \mu \mathrm{g}\right)$. 
Table 2

$\mathrm{RT}$-PCR results in subjects expressed as mean $\pm \mathrm{SD}$ fold increase versus controls for $\operatorname{PrP}^{\mathrm{C}}$ and GRP78 in right and left ventricles.

\begin{tabular}{|c|c|c|c|c|}
\hline & $\operatorname{PrP}^{\mathrm{C}}$ left ventricle & $\begin{array}{c}\text { PrP } \\
\text { ventricle }\end{array}$ & $\begin{array}{c}\text { GRP78 left } \\
\text { ventricle }\end{array}$ & $\begin{array}{c}\text { GRP78 right } \\
\text { ventricle }\end{array}$ \\
\hline Mean & 8.67 & 1.25 & 3.40 & 2.69 \\
\hline Std deviation & 5.91 & 0.86 & 1.69 & 1.35 \\
\hline $\begin{array}{c}\text { p value§ MMC v } \\
\text { Controls }\end{array}$ & 0.0003 & 0.43 & 0.0001 & 0.0002 \\
\hline
\end{tabular}

$\S \mathrm{p}$ values after adjusting for age and gender 


\section{SUPPLEMENTARY TABLES}

Supplementary Table 1 Metropolitan Mexico City subjects, brain Alzheimer's disease staging and cumulative (lifetime) PM 2.5 exposures.

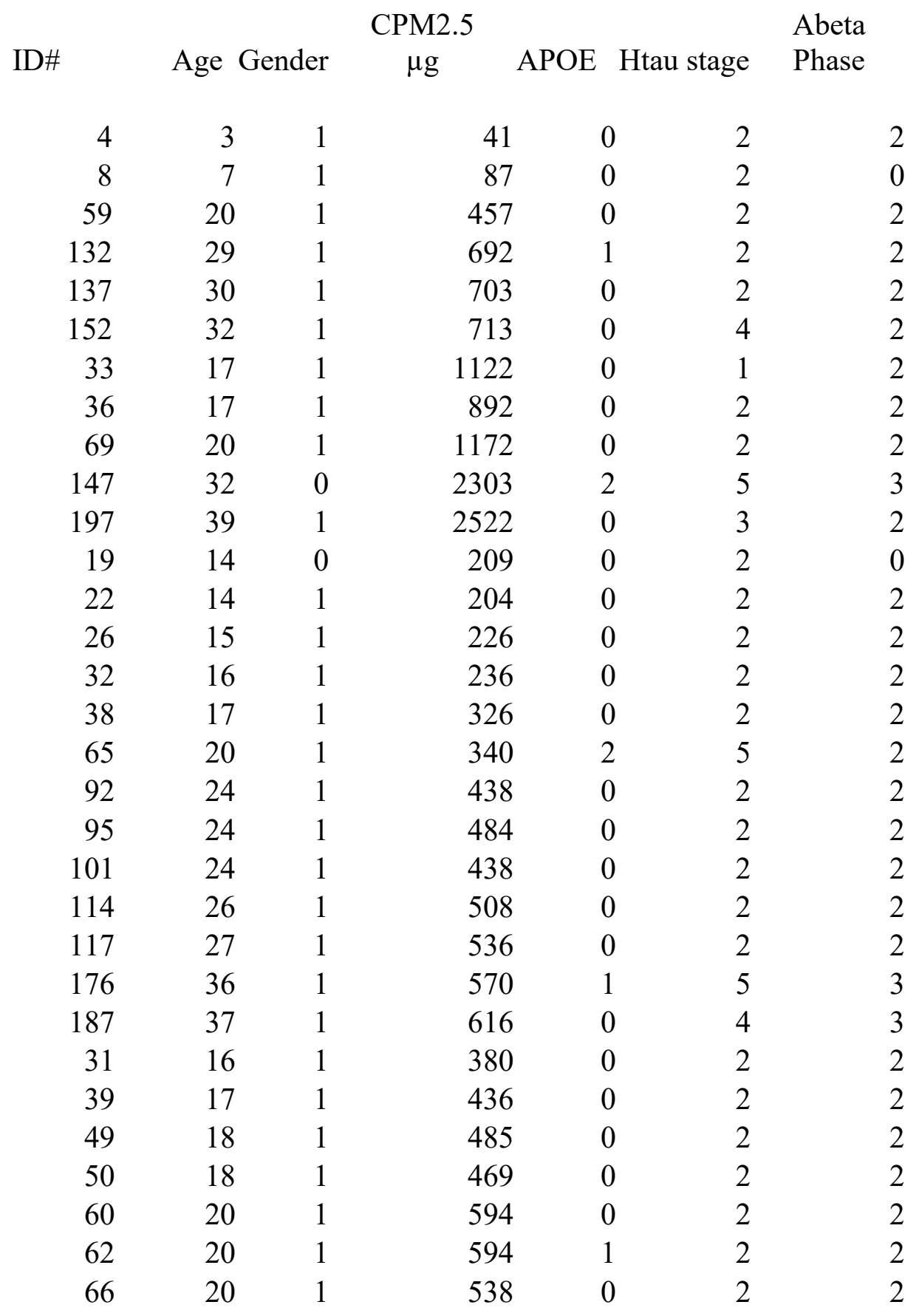




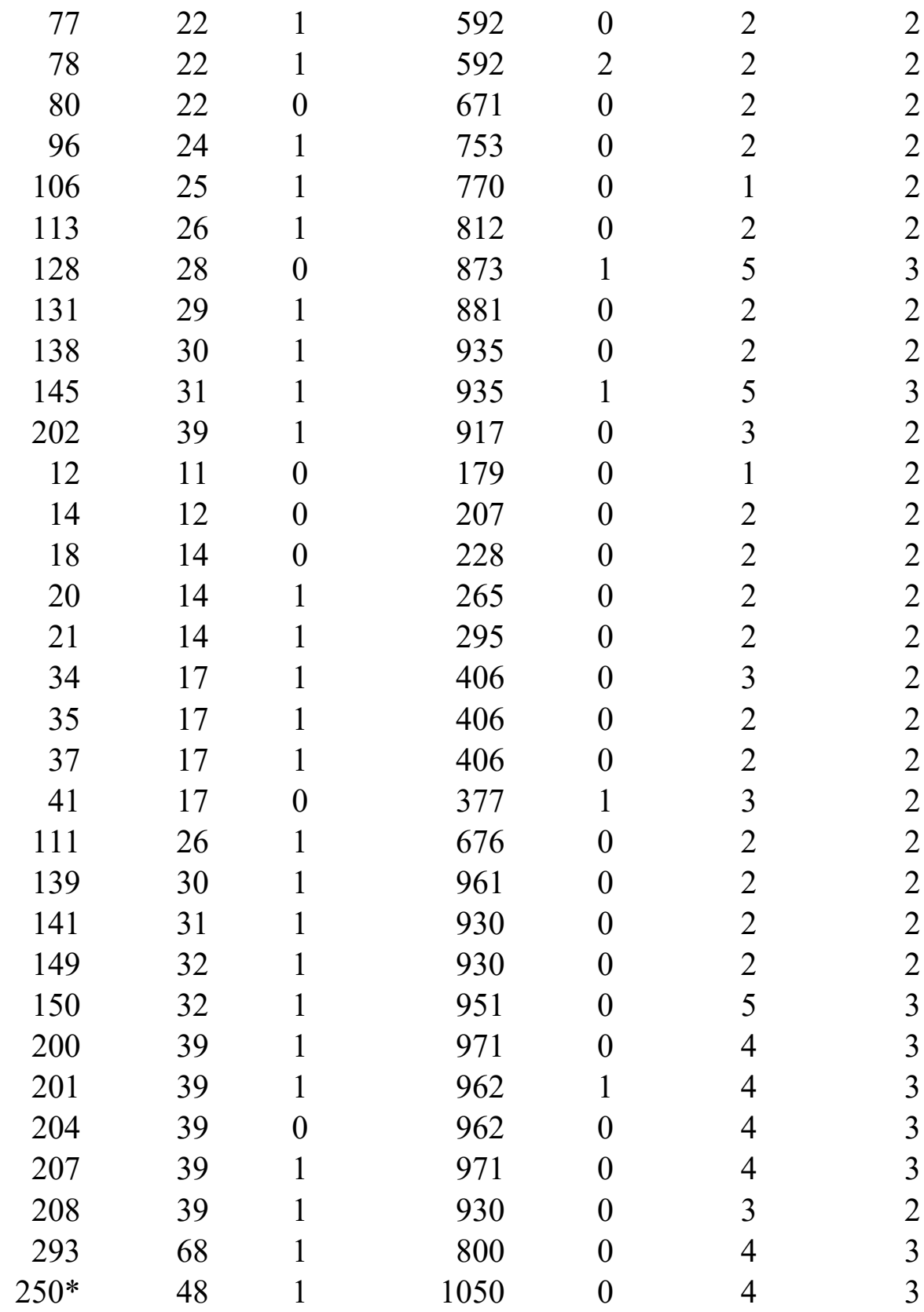

$\mathrm{CPM}_{2.5}$ Cumulative $\mathrm{PM}_{2.5}$ calculated for age at death + pregnancy time, data are in $\mu \mathrm{g} / \mathrm{m}^{3}$ Age: in years Gender: $0=$ female, $1=$ male. APOE $0=3 / 3,1=3 / 4,2=4 / 4$

Htau Stage $^{1-3}$ : 0=absent, 1= pretangle stages a-c, 2= pretangle stages $1 \mathrm{a}, 1 \mathrm{~b}, 3=\mathrm{NFT}$ stages I, II, 4=NFT stages III-IV, 5=NFT stages V-VI

A $\beta$ Phase $^{4}$ : $0=$ absent, $1=$ basal temporal neocortex, $2=$ all cerebral cortex, $3=$ subcortical portions forebrain, 4= mesencephalic components, 5=Reticular formation and cerebellum. 
*Subject 250 corresponds to the heart samples from Figure 4.

1. Braak H, Del Tredici K. 2011. The pathological process underlying Alzheimer's disease in individuals under thirty. Acta Neuropathol 121:171-81 PMID: 21170538 https://ink.springer.com/article/10.1007\%2Fs00401-010-0789-4

2. Braak H, Thal DR, Ghebremedhin E, Del Tredeci K.2011. Stages of the pathological process in Alzheimer disease: age categories from 1 to 100 years. J Neuropath Exp Neurol 70:960-9. PMID:22002422 https://academic.oup.com/jnen/article/70/11/960/2917408

3. Braak H, Del Tredeci K. 2015. The preclinical phase of the pathological process underlying sporadic Alzheimer's disease. Brain 138:2814-33. PMID: 26283673 https://academic.oup.com/brain/article/138/10/2814/2468723

4. Thal DR, Rüb U, Orantes M, Braak H.2002. Phases of A beta-deposition in the human brain and its relevance for the development of AD. Neurology 58: 1791-800. PMID: 12084879 https://www.ncbi.nlm.nih.gov/pubmed/?term=Phases+of $+\mathrm{A}+$ beta$\underline{\text { deposition }+ \text { in }+ \text { the }+ \text { human }+ \text { brain }+ \text { and }+ \text { its }+ \text { relevance }+ \text { for }+ \text { the }+ \text { development }+ \text { of }+ \text { AD }}$ 


\section{Supplementary Figure 1}

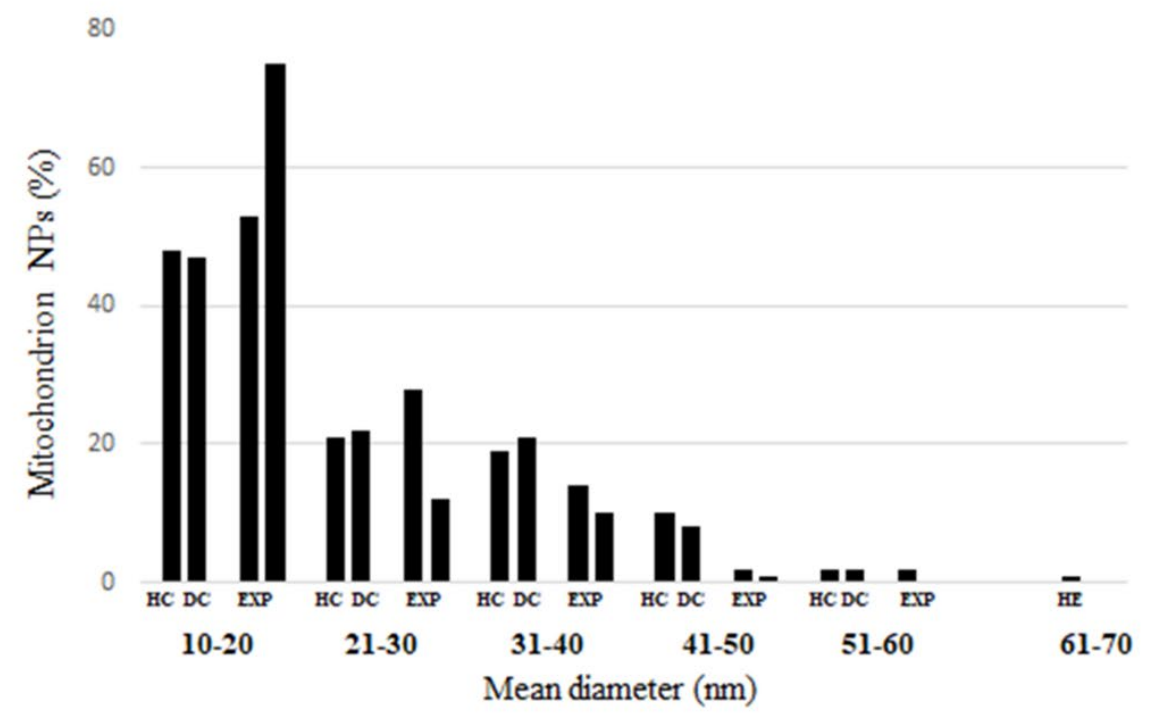

Supplementary Figure 1. The nanoparticle size distribution in percentage of the typical rounded shape pollution 'nanospheres', rich in Fe and other associated transition metals in cardiomyocytes' mitochondria in dogs and humans, both control and MMC. HC human controls, DC dog controls, EXP columns correspond to H and D 